\title{
Scientists join the dots between lady beetles in Iran
}

\begin{abstract}
Lady beetles are toxic to predators and display a

colourful warning - the perfect example of aposematism. After tasting a bitter lady beetle,

to avoid in future. As a result,

lady beetles of certain colour patterns are less likely to be eaten. Copying successful lady beetles helps to avoid predation. Professor Oldrich Nedvèd from the University of South Bohemia set out to investigate this phenomenon, known as Müllerian mimicry, in and discovered a new species

in the process.
\end{abstract}

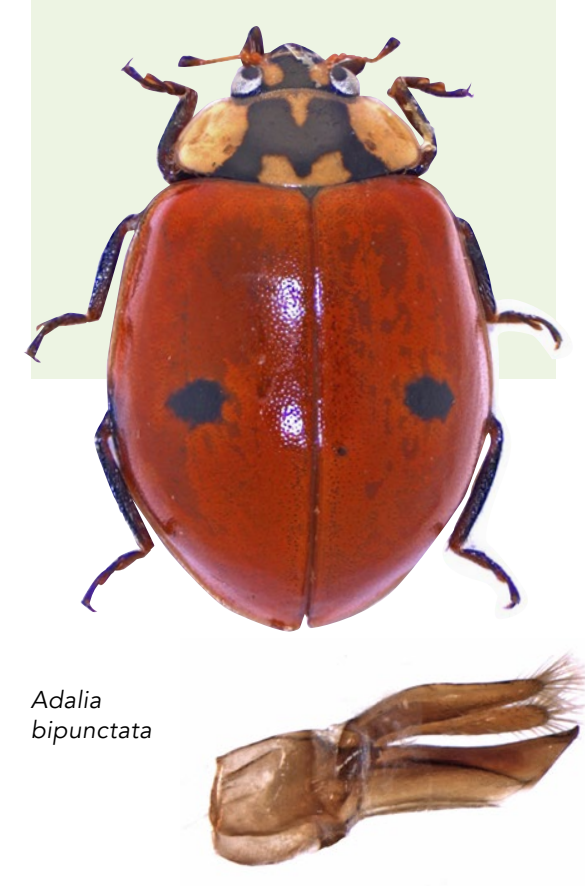

occinellidae, more commonly known as lady beetles, ladybug or ladybirds, are a well-kno family of beetles that are easy to dome-shaped bodies Lady betes, range in colour from cream to dark red and can have few or many black spots on their wing covers (also called elytra). The are over 6000 known species of lady beetle worldwide and there are hundreds of unique colour patterns. However, some species are polymorphic, which means individuals from the same species can have different colour patterns (also known as morphs). This is controlled by genetics and is similar to the control of eye colour or hair colour in humans.

Generally, lady beetles have a bright colour which acts a warning know

beetles that look more like each other are collely to be eaten. This resemblance is called mimicry. The two most commonly and Müllirich one harmless, tasty species resembles achemically protected on Millerian mimicry is when chemically protected species resemble each other In both examples of mimicry, individuals of on species change their colour pattern during evolution to resemble anothe The original, constant species is called a model. The changed species is called a mimic.

Mimicry, and the general evolution and ecology of lady beetle colouration, is of particular interest to Professor Oldinch Nedvěd at the University of South Bohemia. Pofessor Nedved has been

Most of Adalia bipunctata in orchards in Chaharmahal and Bakhtiari province had a pink background and a narrow brown stripe at the suture like Oenopia conglobata.

colouration signals to visual predators that years and has published multiple scientific lady beetles are protected by chemicals that make them toxic and distasteful. Nedved along with his colleagues, Am Birds and other predators that hunt using Biranvand, Mehdi Zare Khormizi and sight, then learn various distasteful colour Derya Şenal, have focused their research patterns (such as red-and-black or yellow- of lady and-black patterns) and avoid them in the future. The quicker predators memorise prey they will eat. With this in mind, lady

NAMING SPECIES

Professor Nedvěd and his colleagues studied three lady beetle species: Adalia

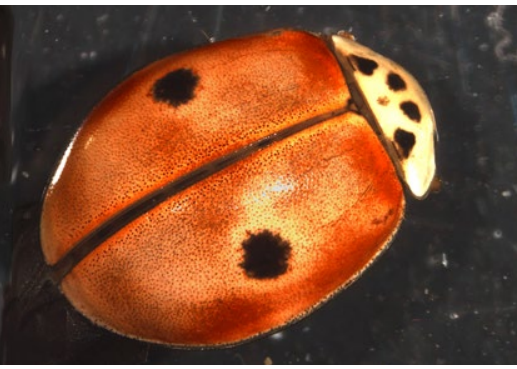

Adalia bipunctata typical form

bipunctata, Oenopia conglobata and Oenopia shirkuhensis. Scientists refer to species by their full Latin names. The first name is the genus and it gives an indication that the species is genetically similar to other species with the same genus name than to species of differen genera. Of these three lady beetles, Oenopia conglobata and Oenopia genus can be abbreviated as an inibl. The second name is the species and can be more descriptive. For example Mehd Zare Khormizi named O shirkuhensis after the Shirkuh Mountain where it was discovered.

Polymorphic species can also have an extra name that describes their colour morph. In Iran, A. bipunctata has four different morphs. The most common morph is orange-red with two spots and is called A. bipunctata forma typica. Forma means form (or morph) and can be abbreviated, and typica describes the particular morph. The other morph can be orange-red with 14 spots (f. fasciatopunctata). O. conglobata also has many colour forms, but the typical and a narow black strike a he spots seam where the wing covers meet).

\section{CHANGING SPOTS}

mahal and Bakhtiari province, Iran, Professor Nedvěd and his colleagues studied the colouration of $A$. bipunctata and $O$. conglobata To do this, the scientists collected observed their colles from trees and minute mophological characters under minute morphological characters under A. bscope. They found that most of the A. bipunctata f. fasciatopunctata they collected had a pink background with a narrow brown stripe at the suture. Pink is by a having layer of red pigments over a white layer deeper in the elytra.
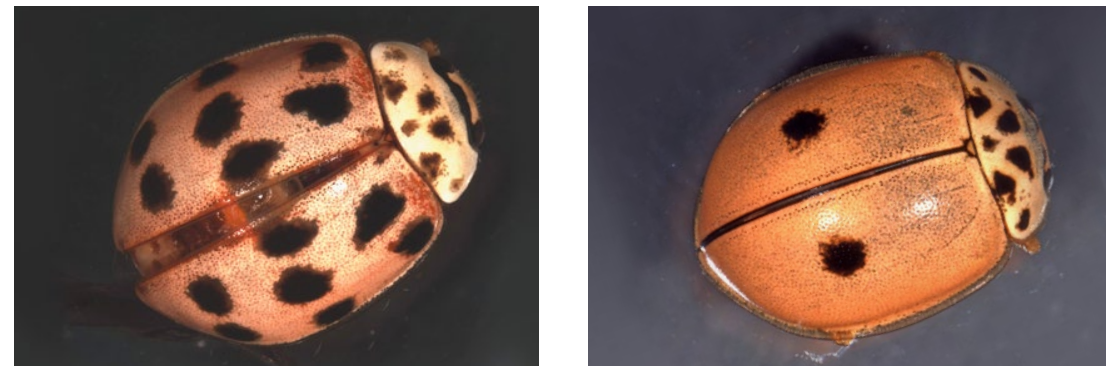

Adalia bipunctataf. fasciatopunctata mimic

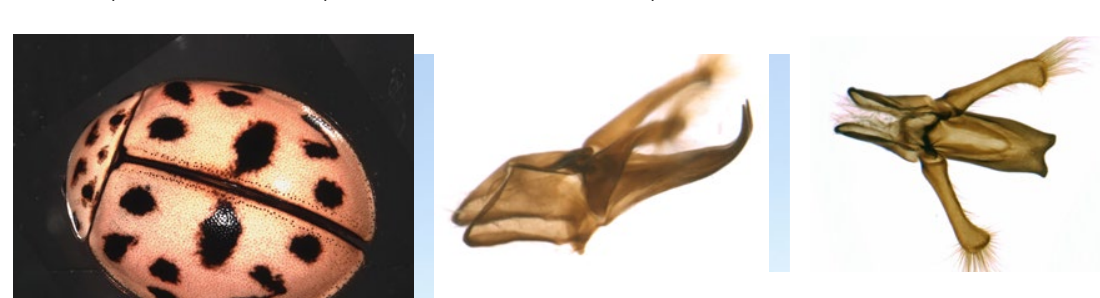

Left: O. conglobata model. Middle: $O$. conglobata
genitalia. Right: O. conglobata genitalia outer view.
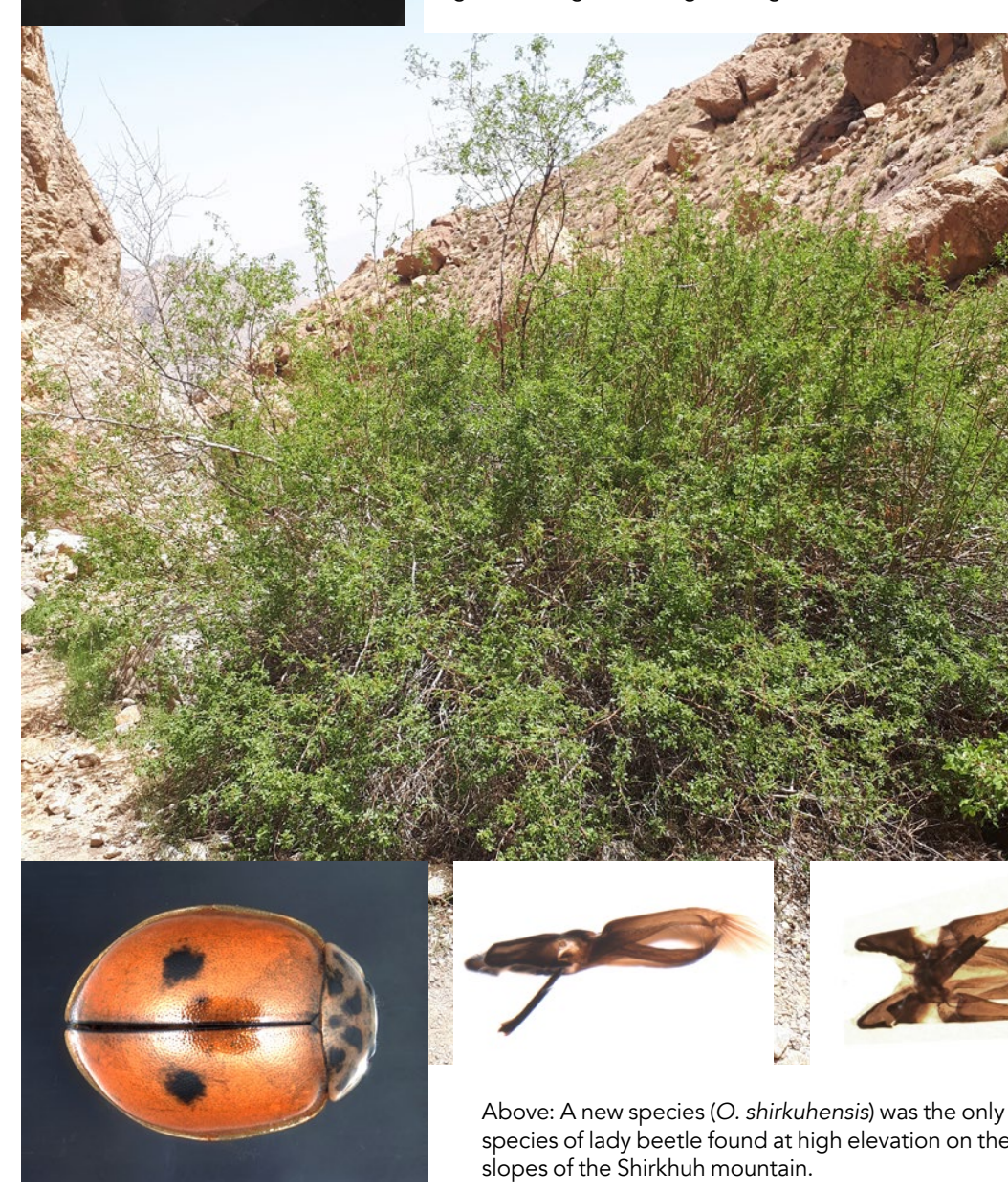

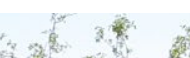
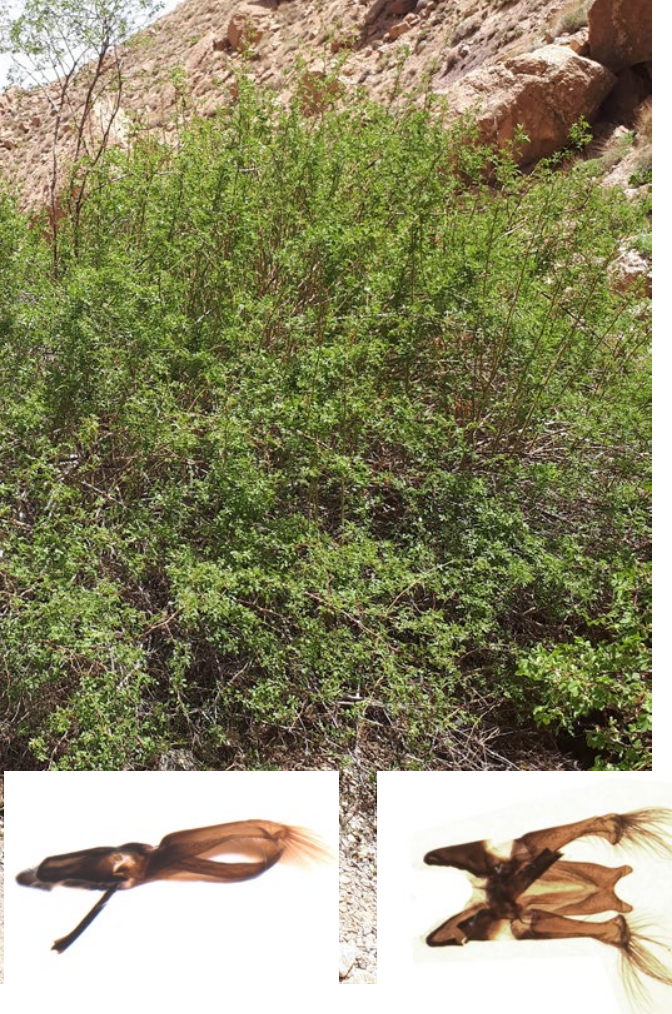

Above: A new species (O. shirkuhensis) was the only
species of lady beetle found at high elevation on the species of lady beetle found at high elevation on the
slopes of the Shirkhuh mountain.

The scientists suggested the similarities can be explained by Mullerian mimicry, where $O$. conglobata is the model species and A. bipunctata f. fasciatopunctata is the mimic. The mimic, A. bipunctata f. fasciatopunctata did not change their spots, but added a suture stripe that is species live in the same isolated orchards surrounded by the mountains and are environment provides the opportunities cases, groups of more than two similarly mimicy rings However, this generaly mimicry rings. However, this generally occurs when the mimic
live in the same place. vulnerable to the same predators. This for selection of matching colours. In some 


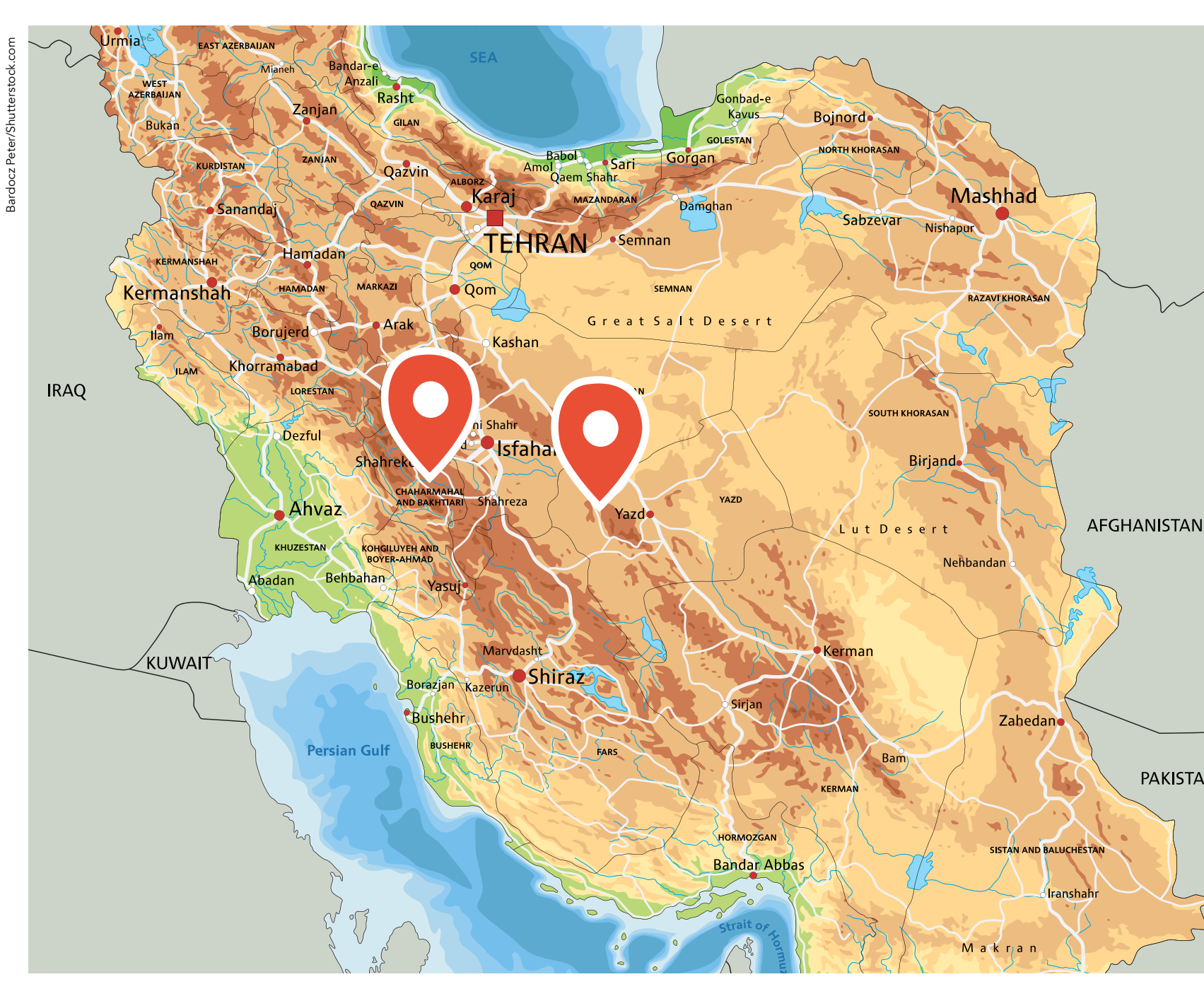

In Chaharmahal and Bakhtiari province, O. conglobata is the model species and A. bipunctata is the mimic. However, in Yazd and Kerman province,

\section{DISCOVERING NEW SPECIES}

Iran Professor Nedvat ances,

colleagues discovered and described

a new species of lady beetle:

O. shirkuhensis. This new species

was the only species of lady beetle

found at high elevation on the
In the diverse mountain habitats

there were four known Oenopia species in Iran. Besides the shape of gentalla, O. shirkuhensis can be also by the ornge other Oenopia species by the tor rounded black spots.

Although the colour pattern of

Professor Nedvěd and his colleagues discovered and described a new species of lady beetle: Oenopia shirkuhensis resembling Adalia bipunctata.

slopes of the Shirkhuh mountain. The the orange-red common form of $A$. scientists took body measurements bipunctata f. typica, the placement and photographs, and also dissected of the spots is identical to the the male genitalia from the beetles as largest spots on $O$. conglobata. The insect species. Up until this discovery,
insenly evolved from $O$. conglobata ey became isolated on the Whirkuh mountain.

\section{BIDIRECTIONAL}

\section{MÜLLERIAN MIMICRY}

In Chaharmahal and Bakhtiari province, and A. bipunctata is the mimic. Here,

A. bipunctata $f$ fasciatopunctata adopted a pink background that is not found elsewhere in the species. However, in Yazd and Kerman province A. bipunctata is the model species and the Oenopia genus is the mimic. Here, it is thought that $O$. conglobata increased red colouration and reduced its spots before geographic isolation led to the evolution of a new species (O. shirkuhensis). Considered together, Professor Nedvěd and his colleagues suggest this is an example of bidirectional Mullerian mimicry. The lady and mode in different provinces of

\section{Behind the Research}

\section{Professor Oldřich Nedvěd}

E: nedved@prf.jcu.cz T: $+420721784390 \quad$ W: http://zoo.prf.jcu.cz/index.php/staff-item/ nedved-oldrich/?lang=en

\section{Research Objectives}

Oldrich Nedvěd's research is focused on the biology of ladybirds.

\section{Detail}

\section{Oldrich Nedvěd}

University of South Bohemia, Faculty of Science and Biology Centre of the Czech Academy of Sciences, of Entomology

Ceské Budějovice, Czech Republic

Bio

Oldrich Nedvěd received his MSc. in Entomology from Charles University, Prague in 1989 and his PhD in Entomology at the Institute of Entomology, Czech Academy of Sciences, Ceské Budějovice in 1995. He became Associate Professor of Zoology, University of South Bohemia, České Budějovice 2000 and Professor of Zoology 2020

\section{Funding}

Arant agency of the Czech Republic, grant number 20

\section{Collaborators}

Mehdi Zare Khormizi and Derya Senal.

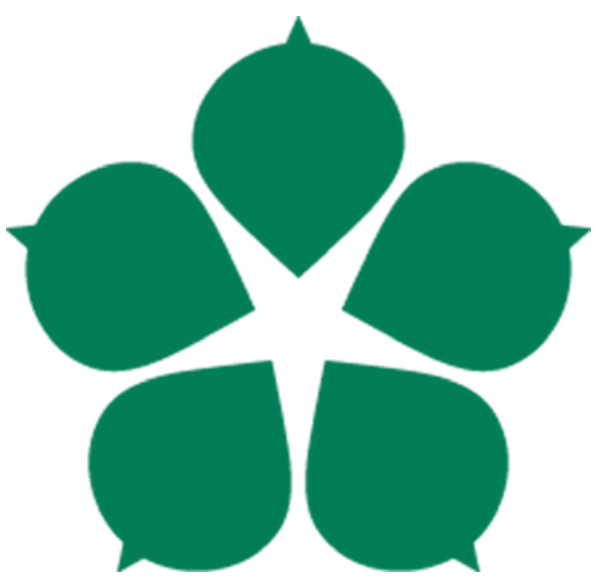

\section{References}

Khormizi MZ, Nedvèd O. (2020). Oenopia shirkuhensis sp. nov. (Coleoptera, Coccinellidae) from lran mimicking Adalia bipunctata. ZooKeys 915: 107-116. doi:10.38971 zookeys. 915.46390

Nedvěd O, Biranvand A, Shakarami J, Senal D. (2020). Potential Mullerian Mimicry between Adalia bipuncta (Coleoptera: Coccinellide) in Iran. The Cols) Bulletin 74(1): 161-167. https//doi org/10.1649/0010065X-74.1.161

\section{Personal Response}

\section{What inspired you to study lady beetles?}

II When I entered Charles University in 1984, I met Dr Ivo Hodek, who was a world-leading specialist on this family of beetles, with contacts to many other specialists whildwide. He wrote a book about ladybirds in 1973 beetles. He became my supervisor. Another teacher who showed me ecology of these beetles in the field was Alois Honěk, and lvo Kovár taught me taxonomy of the group. The fact that these beetles are favourite ones of mapy people and these bee las are favourte

\section{Are there many other examples of bidirectional}

II Mimicry usually has one species as model and sexual mimicry appears to be bidirectional. Some individuals of both sexes have been observed to mimic the behaviour of the opposite sex at their lek. There are numerous possible examples of interspecific resemblance in song components and plumage among warning signals 'character convergence' of phen's should occur. In insects, wing patterns of the Heliconius butterflies exhibit local convergence. 